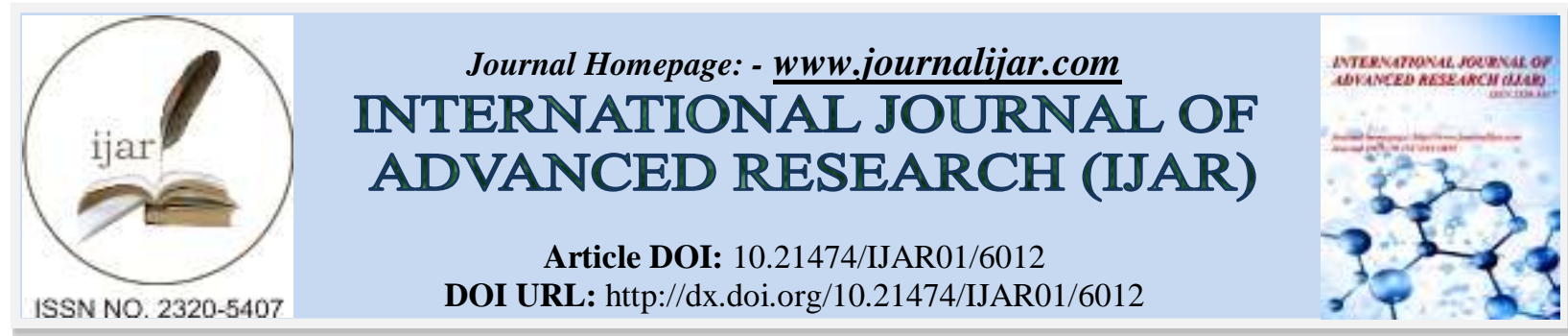

RESEARCH ARTICLE

\title{
MOTIVATION, EXPECTATIONS AND BENEFITS OF THE INTRODUCTION AND MAINTENANCE OF THE VOLUNTARY ENVIRONMENTAL LABELS IN THE TOURISM SECTOR: A STUDY OF ITALIAN COMPANIES.
}

\author{
Romana Gargano. \\ University of Messina.
}

\section{Manuscript Info}

Manuscript History

Received: 09 October 2017

Final Accepted: 11 November 2017

Published: December 2017

Key words:-

MCA, Cluster analysis, Italian tourism companies, environmental labels.

\begin{abstract}
In the recent years the number of tourism enterprises that achieve environmental certification, such as Ecolabel, ISO 14001 and EMAS has increased. The aim of this study is know the reasons that led to undertake the environmental certification process, the advantages recognized by companies and any limitations arising from the certification itself.

In this paper are analysed the environmental sustainability behaviour of Italian tourism companies through different profiles of motivation for the implementation of sustainable measures and generic business variables.

The analysis starts running a factor analysis to reveal the underlying factors in the data. Based on the multiple correspondence analysis, a non-hierarchical cluster analysis is performed to segment the sample into homogeneous groups.

Finally, a Cumulative Proportional Odds Model was used to identifying the dependence of judgment about the environmental certification by previous experience and by the company's expectations with regard to potential benefits.

The study clearly identifies two clusters of companies, where the most discriminating factors are the environmental labels, the future behaviour and the benefits received. The judgment on the environmental certification labels is statistically influenced by to having the corporate and institutional benefits, by the increasing customer loyalty and by encountering obstacles.
\end{abstract}

Copy Right, IJAR, 2017,. All rights reserved.

\section{Introduction:-}

Environmental protection has become a topical issue for tourism in recent years. Tourism, in fact, plays a key role in sustainable development for the strong growth dynamics that have characterized it in recent decades. It represents an important economic contribution for the strong impact that it generates on material and immaterial resources. According to the World Commission on Environment and Development (WCED, 1987, 2) "sustainable development is development which meet the needs of these presents without compromising ability of future generations to meet their own needs". In 1988 the World Tourism Organization defined sustainable tourism activities those that were 
"developed in a way to remain alive in a tourist area for an unlimited period of time without causing environmental, social and artistic alterations and without inhibiting the development of their social and economic activities".

Sector studies show that the tourism industry and its customers' participation in tourism sustainability is still too limited to the potential economic and competitive advantages and to the risk of harming and destroying the environment of the destination. One of the main reasons for the insufficient sustainability of tourism is the lack of visibility and recognisability of the environmentally friendly tourist enterprise, which leads the potential "sustainable" tourist-customer not to be able to make the desired choice. In this context, certification programs and eco-labels can play a fundamental role in promoting sustainable tourism products and thus be a basic tool for promoting environmentally friendly accommodation establishments. The role of environmental certification initiatives is to help traveller to make choices of environmental responsibility; to encourage improvements and standard rules for the tourist establishments. Accommodation companies can benefit economically from certification, not only with lower budget costs (energy saving, water saving, saving on waste production, saving on the use of detergents, etc.) but also with a higher competitiveness compared to non-certified establishments.

Since the 1990s, tourism companies, mostly accommodations establishments, have undertaken different voluntary initiatives to show their commitment to sustainable tourism (Kirk, 1998, Ayuso 2006). Among the voluntary instruments applied to the hotels industry, the most common are codes of conduct, best environmental practices, eco-labels, environmental management systems (EMS) and environmental performance indicators. EMS has become enshrined in international standards such as the EU eco-management and audit scheme (EMAS), the International Organization for Standardization's standard for environmental management systems ISO 14001 and the European Eco-label mark applied to products and services.

In particular, ISO 14001 and EMAS schemes are applicable to organizations on a voluntary basis and allow to obtain certification (or registration) related to the processes and to management mode of environmental aspects by organizations. ISO 14001 is a scheme to manage its environmental responsibilities in a systematic manner for contributes to the environmental sustainability. Consistent with the organization's environmental policy, it includes the enhancement of environmental performance, the fulfilment of compliance obligations and the achievement of environmental objectives. The Eco-Management and Audit Scheme is developed in 1993 by the European Commission and revisited in 2001. It enables organizations to assess, manage and continuously improve their environmental performance. The scheme is globally applicable and open to all types of private and public organizations. All organisations listed in the EMAS register run an environmental management system according to the EMAS requirements. However, ISO 14001 is an integral part of EMAS, these organisations automatically comply with the requirements that the international standard demands as well, and EMAS registered organisations fulfil requirements that go beyond the scope of ISO 14001.

The EU Ecolabel is an international scheme created in 1992 (with the European Regulation CEE 880 and modified with Regulation CE 1980/2000), in order to "promote the design, production, marketing and use of products which have a reduced environmental impact during their life cycle" (EU, 1992). Currently the EU Ecolabel covers 26 product and service groups including tourist accommodation since 2003 and camping to 2005. The aim is therefore to certify the environmentally friendly products and/or practices of a company, and consequently, in the tourism industry, to provide numerous benefits for the tourist companies, tourists and society in general. Dabeva (2013) summarises the benefits of ecolabels in the hotel industry as: improved image of the company, increased product and company competitiveness, a signal for the tourists about the product characteristics, improved product quality. The present study attempts to contribute to the understanding of what and why companies adopt environmental sustainability practices. In particular, this paper analysed Italian hospitality managers' experiences towards sustainability environmental schemes and identify the factors that influence them.

The final objectives of this research are:

1. To identify different segments of tourism companies according to their motivations and experiences towards the environmental certifications. In particular, this papar considers the motivations linked to costs, the time spent on obtaining environmental tool, and the experience as regarding the benefits encountered.

2. To study the effects of variations of companies characteristics on the cluster memberships.

3. To identify the dependence of judgment about environmental labels on experience and the company's expectations with regard to potential benefits. 
The empirical findings provided in this paper give managers, local government and policy makers' valuable information to formulate private and public development and marketing strategies for the development of the sustainable tourism.

This paper is organized as follows. The next section summarizes the main literature regarding the sustainable tourism and the environmental quality certification path. The section 3 introduces the survey study followed by the description of the methodology used in the present research to continue with the main findings of the factorial and classification techniques applied. Finally, in the last section reports the main conclusions.

\section{Previous literature:-}

In the last two decades, the trend toward environmental or sustainable certification has increased. Various studies have shown that commitment to environmental practices improves hotels' financial performance (e.g. Segarra-Oña et al. 2012; Tarí et al. 2010; Zhang et al. 2012), and numerous researches have shown a growing consensus on the sustainable practices for the accommodation industry (e.g., Ferrari et al. 2010; Hsieh 2012; Sloan et al. 2012).

There is a great body of empirical literature on the analysis of the motivations leading companies to adopt environmental management systems based on ISO 14001, Ecolabel or EMAS. From an empirical perspective, Bansal and Roth (2000) propose three types of motive that lead companies to implement an EMS based on an international standard of reference: ethical, competitive and relational. Boiral (2007) pointed out that the adoption of ISO 14001 can be driven by institutional pressures and the search for organizational legitimacy in the eyes of the various stakeholders (customers, public authorities, environmental groups), or by internal motivation to improve environmental practices. González-Benito (2005) for the adoption of environmental management systems have distinguished between competitive operational reasons (the implementation of environmental management practices can generate competitive advantages as costs, productivity), commercial competitive reasons, ethical motivations and relational motivations (regulators, community organizations). Their empirical results indicate that the Spanish companies that are pursuing ISO14001 certification show higher levels of environmental awareness and commitment than other companies do and they believe more in the environmental management potential to generate competitive advantages based both on cost and on differentiation. Similarly, Gavronski et al. (2008) identified societal, market, financial and productivity benefits for the adoption of an EMS. Several empirical studies in this area have shown that the external motivation (improved corporate image, marketing, market demand, relations with public authorities, the competitive position) plays a more important role in comparison to internal motivation (the improvement of environmental performance, employee involvement, innovation, cost savings) in establishing an EMS (Boiral, 2007; Yeung and Mok, 2005). Chan and Wong (2006) showed two significant factors that determinate the motivation for implementing ISO 14001 in hotels, the corporate governance and the creation of procedure to identify and provide access to legislation. Duglio et al (2017) emphasise, on the one, that the main motivations for certification are the sustainability awareness by the hospitality managers and the aim to improve the image of the property among guests, confirming one of the main factors in joining this kind of tools - the manager's disposition as showed by Park, Kim, and McCleary (2014). They underline some difficulties in evaluating and quantifying the benefits that persist among the Italian hospitality managers, in fact, their opinions reveal a lack of balance between expectations (the improvement of the corporate image) and related benefits (increase in the guests number) with the consequence that theirs expectations are not satisfied.

\section{Research Design and findings:- Sample and descriptive statistics results:-}

The empirical research was conducted in Italy between July and December 2016. All companies in tourism sector, certified by as Ecolabel, EMAS and ISO 14001 were considered and a simple casual sampling was used in order to select the tourist structures. In this study, 105 companies decided to collaborate. A computer aided telephone interface (CATI) system was used to record responses.

The questionnaire was divided into three main sections, the first "Company profile" (8 questions about legal form, geographic location, structure and type of company, etc.) with the aim to detect if the companies' size is an obstacle to environmental certification, or it constitutes a strategic factor towards the environmental management efficiency and market competitiveness. The second section "Introduction of the certification and maintenance" contain 10 questions with the aim to identify both the motivation and expectations that prompted the company to undertake the path of certification, both the amount of the costs and time that company has incurred for obtaining certification. In 
this section, in the different answers, a motivating indicator linked to the economic activity and the image of company could be individualized. In particular, the response "request certification from customers" can be considered an indicator of the sensitivity of tourism demand to the problem of environmental sustainability. Finally in third section "Certification Experience" (14 questions, for to have information of the obstacles encountered in the certification path, the benefits that the company obtained in the post-certification period, and the company satisfaction). In particular, as regards the internal benefits encountered after the certification, the first four expected responses are directly linked mainly to the savings. In the section relating to reasons that led the tourism companies to take the environmental certify, the existence of a compliance (positive or negative) between expectations and actual benefits was verify in order to determinate whether the certification was the final moment of a savings resources policy started several years before. The results achieved towards the customers in terms of both image and satisfaction that of behaviour was considered apart from the benefits. The questionnaire included closed questions a single answer, dichotomous, Likert scale questions and filter questions.

The $15 \%$ of tourism companies have more than certification but in this research, they have reported only one. In particular, the 49\% ISO 14001 certification, 10\% EMAS and the 41\% Ecolabel certification. The research shows that $73.2 \%$ of companies before certification had resource savings program, that $79.2 \%$ found business benefits (especially for cost cutting to the energetic saving and the recycling); that $34 \%$ has benefited from funding. Table 1 shows the profile of responded companies.

Table 1:- Profile of tourism companies.

\begin{tabular}{|c|c|c|}
\hline & & Percent \\
\hline \multirow{4}{*}{ Type of company } & Individual enterprise & 22 \\
\hline & Partnership & 37 \\
\hline & Capital company & 25 \\
\hline & Other & 16 \\
\hline \multirow{3}{*}{ Location by Italian geographic area } & North & 35 \\
\hline & Centre & 31 \\
\hline & South and Island & 34 \\
\hline \multirow{4}{*}{ Environmental } & Mountain & 37 \\
\hline & Rural & 6 \\
\hline & Sea & 48 \\
\hline & Urban & 9 \\
\hline \multirow{5}{*}{ Type } & Hotel/restaurant & 51 \\
\hline & Camping & 12 \\
\hline & Village & 18 \\
\hline & Farmhouse/Bed and Breakfast & 11 \\
\hline & Other & 8 \\
\hline \multirow{6}{*}{$\begin{array}{l}\text { Business } \\
\text { (in thousands) }\end{array}$} & $<250$ & 21 \\
\hline & $251-500$ & 10 \\
\hline & $501-2500$ & 16 \\
\hline & $2501-5000$ & 2 \\
\hline & $5001-10000$ & 4 \\
\hline & $>10000$ & 47 \\
\hline \multirow{4}{*}{ Opening time } & $<6$ months & 15 \\
\hline & 6-9 months & 41 \\
\hline & 10-11 months & 13 \\
\hline & 12 months & 31 \\
\hline \multirow{5}{*}{ Employs } & $1-9$ & 49 \\
\hline & $10-29$ & 38 \\
\hline & $30-49$ & 6 \\
\hline & $50-99$ & 6 \\
\hline & $>100$ & 1 \\
\hline
\end{tabular}


Table 2 reports the motivations and expectations that have led companies choose a certification of environmental quality.

Furthermore, $62 \%$ of companies has been successful in improving the image but only $1 \%$ has acquired new customers, the $30 \%$ of companies has benefited from institutional support. Finally, were performed the questions to rate the usefully and necessity of environmental certification, ranging from 1 (strongly disagree) to 5 (strongly agree), for $42 \%$ of companies the certification is useful and necessary (strongly agree), for $32 \%$ useful but not necessary (agree), 5\% (indifferent) 14\% (disagree), 12\% (strongly agree) not useful and not necessary.

Table 2:- Motivations and expectations of tourist companies respect to environmental certification (\%)

\begin{tabular}{|l|r|r|l|r|r|}
\hline Motivations & \multicolumn{1}{|c|}{ Yes } & \multicolumn{1}{|c|}{ No } & Expectations & Yes & No \\
\hline Costs reduction and environmental waste & 94.1 & 5.9 & Costs reduction and environmental waste & 97.1 & 2.9 \\
\hline Improving the image & 90.2 & 9.8 & Improving the image & 94.1 & 5.9 \\
\hline Improved efficiency of processes & 55.9 & 44.1 & Improved efficiency of processes & 52.9 & 47.1 \\
\hline Tax relief & 26.5 & 73.5 & New customer acquisitions & 82.1 & 17.9 \\
\hline Customer demand & 15.6 & 84.4 & Customer loyalty & 63.1 & 36.9 \\
\hline
\end{tabular}

In addition, the survey showed that the $75.3 \%$ of companies implemented a resource-saving policy before the certification. The $78.2 \%$ of the tourist companies has found business benefits after having gotten the environmental certification (in particular the $43.5 \%$ for cost reduction related to resource waste, the $20.5 \%$ for increase of recycle and $20.3 \%$ for energy saving, low percentages were found for other). Only the $28.9 \%$ has profited of institutional benefits and the $28.1 \%$ has found obstacles in the run of certification.

\section{Methodology:-}

Due to test the nature of data and aim of research, the statistical analysis has developed in three steps.

In a first step, aimed at finding common latent factors underlying the tourism company's experience, starting from the information available from the original variables. Due to presence of categorical variables, a multiple correspondence analysis (Benzécri, 1973 and Greenacre and Blasius, 2006) was applied. Multiple correspondence analysis (MCA) makes use of contingency tables to find new variables that (i) are the best linear combination of the original variables; (ii) are mutually independent; (iii) concur in explaining a decreasing share of the total inertia (in this research we have used a Bènzecri correction), in order to signal the importance of each factor.

In a second step, after reducing a data dimension, we have applied a non-hierarchical cluster analysis in order to identify groups of accommodation structures with a degree of similarity, using Euclidean distance measure. The kmeans algorithm was apply to classify the companies in clusters. K-means is the most popular non - hierarchical iterative clustering algorithm. The basic idea of k-means is to start with an initial partition and assign data objects to cluster so that the squared error decreases. Subsequently, to judge various aspects of clusters validity measure the goodness of a clustering structure and to compare different clusters, we applied Dunn, and Silhouette as internal clustering criteria (Liu et al 2010).

Dunn's index $(D)$ (Dunn, 1974) is based on the idea of identifying the cluster sets, which are compact and well separated. The Dunn index defines the ratio between the minimal intra cluster distance, $\mathrm{d}_{\min }$, and the maximal inter cluster distance, $\mathrm{d}_{\max }$.

$$
\mathrm{D}=\frac{\mathrm{d}_{\min }}{\mathrm{d}_{\max }}
$$

The Dunn index ranged within the interval $[0,1]$ and should be maximised. If the dataset has compact and wellseparated clusters, the distance between the clusters is expected to be larger and the diameter of the clusters is expected to be smaller. The clusters are compact and well separated by maximizing the inter-cluster distance while minimizing the intra-cluster distance. Large value of Dunn index indicates the compact and well-separated clusters. The Silhouette index $(S)$ (Rousseeuw, 1987) validates the clustering performance based on the pairwise difference of between and within-cluster distance. Silhouette values lies in the range of [-1, 1]. A value of +1 indicates that the sample is far away from its neigh boring cluster and very close to the cluster, it is assigned. Similarly, value of -1 indicates that the point is close to its neigh boring cluster than to the cluster it is assigned. And, a value of 0 means 
its at the boundary of the distance between the two cluster. Value of +1 is idea and -1 is least preferred. Hence, higher the value better is the cluster configuration. The silhouette $\mathrm{S}(\mathrm{i})$ can be calculated as:

$$
S_{i}=\frac{a_{i}-b_{i}}{\max \left(a_{i}, b_{i}\right)}
$$

Where $a_{i}$ is the average dissimilarity of ith-point to all other points in the same cluster and $b_{i}$ is the minimum of average dissimilarity of ith-point to all points in another cluster (in the closest cluster).

Finally in third step, considered the nature of dependent variable (ordinal categorical), a Cumulative Proportional Odds Model (Agresti, 2010; O'Connel, 2006) was used to identifying the dependence of judgment about the environmental certification by the previous experience and by the company's expectations. In the context of PLUM (Polytomous Universal Model) procedure, the logit as link function was used for model estimation. The proportional odds model is a generalization of a binary logistic regression model when the response variable has more than two ordinal categories and it is used to estimate the cumulative probability of being at or below a particular level of the response variable. This model estimates the odds of being at or below a particular level of the response variable. In ordinal logistic regression, the event of interest is observing a particular score or less. For an ordinal variable with $\mathrm{i}$ modalities, it is possible to define the odds as:

$$
\theta_{\mathrm{i}}=\operatorname{prob}(\text { score } \leq \mathrm{i}) / \operatorname{prob}(\text { score }>\mathrm{i})
$$

The last category does not have an odd that is associated with it since the probability of scoring up to and including the last score is one. It is possible also write the previous equation as:

$$
\theta_{\mathrm{i}}=\operatorname{prob}(\operatorname{score} \leq \mathrm{i}) /(1-\operatorname{prob}(\operatorname{score} \leq \mathrm{i})) .
$$

Since the probability of a score greater than $\mathrm{j}$ is 1 minus probability of a score is less than or equal to $\mathrm{i}$. The ordinal logistic model for a single independent variable is:

$$
\ln \left(\theta_{i}\right)=\alpha_{i}-\beta X
$$

Where $i=1, \ldots, \mathrm{i}-1$, with i categories number. Larger coefficients indicate an association with larger scores. The ordinal logistic model is based on the assumption that there is a latent continuous outcome variable and that the observed ordinal outcome arises from discretizing the underlying continuum into i-ordered groups. The thresholds estimate these cut off values. The basic form of the generalized linear model is:

$$
\operatorname{link}\left(\gamma_{\mathrm{i}}\right)=\frac{\theta_{\mathrm{i}}-\left[\beta_{1} \mathrm{x}_{1}+\beta_{2} \mathrm{x}_{2}+\cdots+\beta_{\mathrm{k}} \mathrm{x}_{\mathrm{k}}\right]}{\exp \left(\tau_{1} \mathrm{z}_{1}+\tau_{2} \mathrm{z}_{2}+\cdots+\tau_{\mathrm{m}} \mathrm{z}_{\mathrm{m}}\right)}
$$

Where $\gamma_{\mathrm{i}}$ is the cumulative probability for the $\mathrm{i}$-th category; $\theta_{\mathrm{i}}$ is the threshold for the $\mathrm{i}$-th category, $\beta_{1} \ldots \beta_{\mathrm{k}}$ are the regression coefficients, $\mathrm{x}_{1} \ldots \mathrm{x}_{\mathrm{k}}$ are the predictor variables, and $\mathrm{k}$ is the number of predictors, $\tau_{1} \ldots \tau_{\mathrm{m}}$ are coefficients for the scale component and $z_{1} \ldots z_{\mathrm{m}}$ are $\mathrm{m}$ predictor variables for the scale component.

\section{Empirical results:-}

Table 3 reports the results of MCA and displays the variables reporting the higher value of contributions in each factor. The Benzecri correction index shows that a two-dimensional solution was found more appropriate as they explained $87.32 \%$ of the variance. The singular values (eigenvalues) of the dimensions were 0.31 and 0.21 , meeting the 0.20 criteria for meaningful dimensions. The first dimension explained $63.51 \%$ of the variance while the second dimension explained $23.81 \%$ of the variance. The main contributions to the first factor came from motivation and expectation of higher efficiency of production processes and of the presence of obstacles encountered. Factor 2 was formed mainly by the information on motivation and expectation of improvement of image, the valuation of environmental label and future behaviour.

Table 3:- Multiple correspondence analysis. Factors extracted and highest contributions

\begin{tabular}{|l|r|r|r|r|}
\hline & Eigenvalue & Contribution & \% inertia & \%cum \\
\hline Factor 1 & 0.31 & & 63.51 & 73.52 \\
\hline Motivation of improved of processes efficiency & & 21.50 & & \\
\hline Expectation of improved of the processes efficiency & & 19.71 & & \\
\hline Presence of obstacles encountered & & 12.98 & & \\
\hline Factor 2 & 0.21 & & 13.81 & 87.32 \\
\hline
\end{tabular}




\begin{tabular}{|c|c|}
\hline Motivation of improvement of image & 20.40 \\
\hline Expectation of improvement of image & 19.81 \\
\hline Valuation of environmental label & 18.37 \\
\hline Future behaviour. & 18.09 \\
\hline
\end{tabular}

In the second step, with the aim of classify the tourism companies into internally homogeneous and mutually heterogeneous groups, the $\mathrm{k}$ means cluster method is employed. The cluster analysis was carried out from the quantitative information of the factors extracted from the correspondence analysis. In order to specify the number of cluster desired, we have used the internal clustering criteria as Dunn and Silhouette index. All the criteria ( $\mathrm{D}=0.81$ and $S=0.84$ ) indicate that the optimal number of clusters is two. Table 4 reports the results of $\mathrm{k}$ means cluster analysis. The biggest cluster (63.2\% of sample) was the "motivated" group and it was mainly composed of companies that have been driven to certification by both customers and suppliers (99\%), but also by greater process efficiency $(92.7 \%)$ and by safety of legislative conformity $(83.3 \%)$. The companies not have founds obstacles (87.5\%) and have achieved benefits (82.4). They consider useful the environmental label (96\%) and in future, they will maintain (72\%) and will develop her. The principal goal of these companies is to increase in competitive capacity and acquisition of new customers (100\%); moreover, their main advantage is a cost reduction for inefficiencies or waste of resources (75\%) and an increasing the visibility (62\%). The expectations of these companies concerned above all the increase of the productivity (92\%) and of the staff motivation. They offer a catering (100\%) and village services (80\%) mainly, have gotten the certifications ISO $14001(80 \%)$ and EMAS (60\%) and they generate between 2,5 EUR million and 10 million. These companies are located in lake (100\%) and sea $(64.7 \%)$ area and have a clientele of echo-naturalistic, thermal tourists $(100 \%)$. The second cluster account the $36.8 \%$ of companies. It is the "less motivated" cluster and is mainly made up of companies with Ecolabel (62.3\%), located in rural (99.2\%) and mountain (46.5\%) area. They are Bed and Breakfast and Farmhouse (95\%) mainly and offer services typical of food, rural and mountain tourism. These companies demanded the environmental label without expecting greater process efficiency $(81.5 \%)$ or image improvement (67\%). They encountered obstacles in the certification path (90\%), did not have any benefits (98\%) and they will not renew the environmental quality label in the future. These companies consider the environmental label not sufficiently useful to justify the costs $(66.7 \%)$ and useful but too much expensive (50\%). They have achieved the objective to have a sustainable behaviour from the clients $(51 \%)$.

Finally, in order to verify the possible dependence of the judgment on the company's expectations regarding the possible advantages deriving from obtaining the certification a Cumulative Proportional Odds model was estimated. We have considered as explanatory variables the improvement of image, the increasing and loyalty of customers, the efficiency, the corporate and institutional benefits and the obstacles encountered. Results were reported in Table 4. The model provides a number of constants equal to the number of modes of the response variable less than 1; in the case, it provides 3 constants. According to literature, the Deviance test and the Pearson test have been estimated as measures of goodness of adaptation, both tests show an adequate degree of adaptation of the model to observed data ( $p$-value 0.123 and p-value $=0.101$ respectively). Next, with the aim to measure the association level between the dependent variables and the predictor we have estimated the Pseudo R square measurements (such Cox and Snell and Mc Fadden tests) that have denoting an adequate fit. The estimate model shows that obtaining corporate and institutional benefits, the customer loyalty and encountering obstacles have significantly influence on judgment. In particular, greater benefits are associated with higher judgment while greater difficulties determine lower judgments. Moreover, regarding the customer loyalty the negative sign of the coefficient denotes that the judgment is very more positive as less a company expects to gain benefits in terms of customer loyalty, or express higher ratings those companies that expect less feedback from the benefit of customer loyalty. Therefore, there seems to be the "unexpected" loyalty of the customer among the many positive effects of environmental certification.

Table 4:- Cumulative Proportional Odds Model - Estimated model

\begin{tabular}{|l|r|r|r|r|}
\hline Variable & Coefficients & Standard error & Wald & p-value \\
\hline Constant 1 & 0.671 & 1.489 & 0.203 & 0.075 \\
\hline Constant 2 & 1.391 & 1.504 & 0.855 & 0.067 \\
\hline Constant 3 & 2.302 & 1.534 & 2.252 & 0.053 \\
\hline Image improving & 1.935 & 1.585 & 1.490 & 0.222 \\
\hline Customer increasing & 0.304 & 0.843 & 0.130 & 0.718 \\
\hline Customer loyalty & -2.015 & 0.932 & 4.676 & $\mathbf{0 . 0 3 1}$ \\
\hline
\end{tabular}




\begin{tabular}{|l|r|r|r|r|}
\hline Efficiency improving & 1.527 & 0.839 & 3.307 & 0.069 \\
\hline Corporate and institutional benefits & 2.687 & 1.073 & 6.271 & $\mathbf{0 . 0 1 2}$ \\
\hline Obstacles & -1.825 & 0.931 & 3.844 & $\mathbf{0 . 0 4 8}$ \\
\hline
\end{tabular}

\section{Conclusions:-}

Even though the environmental sustainability sector has been experiencing a remarkable growth in recent years, to the best of the authors' knowledge, only a few papers have investigated experience and satisfaction of Italian accommodation enterprises. This study contributed to this strand of the literature by analysing characteristics, motivations, expectations and experiences of tourism companies.

The main results of this paper show both strong and critical point in the adoption of the environmental certification by the Italian tourism companies.

The multidimensional approach to data has allowed us to highlight some important factors on the experience of the environmental certification process undertaken by tourism companies. In particular, it showed how, in relation to the different objectives, tourism companies adopt similar behaviours to obtain different agglomerations, expression of different experiences and intentions of the company.

In the dataset, the two latent dimensions that explained an important part of the inertia according to the multiple correspondence analysis were extracted. A non - hierarchical cluster analysis was then performed from the extracted factors in order to identify a set of clusters of tourism companies that have an environmental label. In every group, similar features, motivations and experiences characterized companies. The $\mathrm{k}$ - means analysis highlighted two segments of tourism companies with different profiles, for example environmental label, area, future intentions with respect the environmental quality label. The "motivated" cluster is the largest, it comprises companies with ISO 14001, and EMAS, with the principal aim to increase in competitive capacity and acquisition of new customers and their main advantage is a cost reduction for inefficiencies or waste of resources and an increasing the visibility.

The "less motivated" cluster is mainly made up of companies with Ecolabel that have demanded the environmental label without expecting greater process efficiency or image improvement. They encountered obstacles in the certification path and did not have any benefits but have achieved the objective to have a sustainable behaviour from the clients. These companies consider the environmental label not sufficiently useful to justify the costs and useful but too much expensive. They will not renew the environmental quality label in the future.

Finally, the express judgment on the environmental certification labels is statistically influenced by having the corporate and institutional benefits, by the increasing customer loyalty and by the encountering obstacles.

In conclusion, without underestimating the importance of other organizational members, the managers have a fundamental role in starting and leading the organizational change towards the environmental sustainability culture, since these environmental labels, besides communicating the environmental commitment, favour improved reputation and allow you to gain an advantage in the competitive market.

\section{References:-}

1. Agresti A., (2010): Analysis of Ordinal Categorical Data, 2 edition, Hoboken, NJ: Wiley.

2. Ayuso, S., (2006): Adoption of Voluntary Environmental Tools for Sustainable Tourism: Analysing the Experience of Spanish Hotels. Corp. Soc. Responsib. Environ. Mgmt. 13: 207-220

3. Bansal P, Roth K. 2000. Why Companies go Green: A Model of Ecological Responsiveness. Academy of Management Journal 43 (4): pp. 717-736.

4. Benzécri J. P. (1973): L’Analyse des Données, Tome I: L'Analyse des Correspondences. Dunod Paris.

5. Boiral, O. (2007). Corporate greening through ISO 14001: a rational myth? Organization Science, 18(1), 127146.

6. Calinski RB, Harabasz J: A dendrite method for cluster analysis. Communications in Statistics 1974, 3:1-27

7. Chan, ES and Wong, SC (2006) Motivations for ISO 14001 in the hotel industry Tourism management, 27 (3): 481-492.

8. Chapman and Hall, London.

9. Cornell Hospitality Quarterly, 53 (3): 242-56. 
10. Dabeva, T. (2013). The role of international eco certification system in the hotel industry. Proceedings of the Sixth Black Sea Tourism Forum, Varna, Bulgaria, pp 149-160.

11. Duglio S., Ivanov S, Magliano F., Ivanova M. (2017): Motivation, costs and benefits of the adoption of the European Ecolabel in the tourism sector: an exploratory study of Italian accommodation establishments, Izvestiya, 61, 1, 83-95.

12. Dunn J. (1974): Well separated clusters and optimal fuzzy partitions, J. Cybern, 4 (1): 95-104.

13. Ferrari, G., Mondéjar-Jiménez J., and Vargas-Vargas M. (2010): Environmental sustainable management of small rural tourist enterprises. International Journal of Environmental Research 4 (3): 407-14

14. Gavronski I., Ferrer G., Paiva E.L. (2008): ISO 14001 certification in Brazil: motivations and benefits. Journal of Cleaner Production 16 (1): 87-94.

15. Gonzàlez-Benito, J and Gonzàlez-Benito O (2005), An Analysis of the Relationship between Environmental Motivations and ISO14001 Certification, British Journal of Management, 16, 2, pp133-148.

16. Greenacre, M.J., Blasius, J. (2006) Multiple Correspondence Analysis and Related Methods.

17. Hsieh, Y. 2012. Hotel companies' environmental policies and practices: A content analysis of their web pages. International Journal of Contemporary Hospitality Management 24 (1): 97-121

18. International Journal of Hospitality Management 29 (3): 500-10.

19. Kirk, D., (1998): Attitudes to environmental management held by a group of hotel managers in Edinburgh. International Journal of Hospitality Management 17: 33-47.

20. Liu Y., Li Z., Xiong H., and Gao X, Wu J. (2010): Understanding of Internal Clustering Validation Measures, In IEEE ICDM, pages 911-916, 2010.

21. O'Connell, A.A. (2006): Logistic regression models for ordinal response variables. Thousand Oaks: Sage.

22. Park, J., Kim, H.J., \& McLeary, K.W. (2014): The Impact of Top Management's Environmental Attitudes on Hotel Companies' Environmental Management. Journal of Hospitality \& Tourism Research. 38. p. 95-115.

23. Rousseeuw P. (1987): Silhouettes: a graphical aid to the interpretation and validation of cluster analysis. J. Comput. Appl. Math. 20 (1): 53-65.

24. Segarra-Oña, M., A. Peiró-Signes, R. Verma, and L. Miret-Pastor. (2012): Does environmental certification help the economic performance of hotels? Evidence from the Spanish hotel industry.

25. Sloan, P., W. Legrand, and J. S. Chen. 2012. Sustainability in the hospitality industry. Principles of sustainable operations, 2nd ed. Oxford, UK: Routledge.

26. Tarí, J. J., Claver-Cortes E., Pereira-Moliner J., and Molina-Azorín J. F. (2010): Levels of quality and environmental management in the hotel industry: Their joint influence on firm performance.

27. Yeung G., Mok V. 2005. What are the impacts of implementing ISOs on the competitiveness of manufacturing industry in China? Journal of World Business, 40: 139-57.

28. World Commission on Environment and Development (WCED). Our common future. Oxford: Oxford University Press, 1987. pp. $1,8$.

29. Zhang, J. J., Joglekar N., and Verma R., (2012). Pushing the frontier of sustainable service operations management: Evidence from US hospitality industry. Journal of Service Management 23 (3): 377-99. 